\title{
Socioeconomic status and changes in body mass from 3 to 5 years
}

\author{
M De Spiegelaere, M Dramaix, P Hennart
}

\begin{abstract}
The influence of social status on the development of body mass was analysed in a retrospective cohort study of 675 Belgian children monitored between the ages of 3 and 5 years by the preventive medical services in Brussels. At age 3, no association between excess weight and social status was observed. Adiposity rebound before age 5 was inversely related to body mass at age 3 and was independent of social status. The social influences on obesity observed in adolescence cannot be explained by a higher frequency of early adiposity rebound in children of low socioeconomic status.

(Arch Dis Child 1998;78:477-478)
\end{abstract}

Keywords: socioeconomic status; adiposity rebound; obesity

In industrialised countries adult obesity is associated with lower social status. ${ }^{1}$ Social class variation of obesity is increasing. ${ }^{2}$ If we are to develop preventive strategies, we must determine at what stage of life these differences develop.

There is little published research on the relation between social status and obesity in preschool children and what there is generally concludes that there is no connection. ${ }^{13}$ The relation in adults seems to develop during adolescence. $^{4-6}$

Longitudinal studies of body mass during the period of growth indicate that obesity observed clinically in adolescence begins much earlier and especially at the time of adiposity rebound. ${ }^{78}$

Changes in relative fatness with age occur simultaneously with changes in fat cell size or fat cell number. During the first year of life, adiposity increases rapidly owing to the growth in the size of the adipocytes. In the following years, adipose tissue growth decreases and then remains stable for several years, while body height continues to increase. This development is reflected by a decrease in relative fatness. The onset of the second period of rapid growth in body fat is referred to as "adiposity rebound." "

The age of adiposity rebound, which on average is between 5 and 6 years, is negatively correlated with body mass at the end of the growth period: the earlier the rebound, the greater the body mass at that time. ${ }^{78}$ This period has thus been identified as one of the critical periods for the development of obesity. ${ }^{9}$

We aimed to determine whether social inequalities in obese adolescents can be explained partly by differences in the evolution of body mass during the period of adiposity rebound.

\section{Methods}

Our sample was 2645 children born between 1986 and 1990 from those attending the preventive medical services in the Brussels region. The children's files were selected to obtain nearly 500 files in each of five social groups, defined according to parents' professions and the status of their activity (active or inactive; out of work; disabled, etc). Group 1 were active members of upper management and professionals; group 2, white collar workers; group 3, active self employed and technicians; group 4, active manual workers; and group 5, those not working (unemployed, disabled, retired) or dependent on state assistance. Allocation to the different social groups was made on the basis of the parent with the most favourable socioeconomic status.

We excluded immigrant children, and selected only Belgian children for whom data on weight and height were known for ages 3 and 5, providing a group of 675 children (328 girls and 347 boys): 146 in group 1, 197 in group 2, 139 in group 3, 113 in group 4, and 80 in group 5.

The mean (SD) age for the examination planned for age 3 was 36.4 (3.1) months and for age $5,61.3(4.6)$ months. The mean age at these examinations did not differ according to social group.

Excess weight was defined by a body mass index (BMI; weight $(\mathrm{kg}) /$ height $\left.^{2}\left(\mathrm{~m}^{2}\right)\right) \geqslant 95$ th centile of the distribution for age and sex. ${ }^{10}$ Body mass curves show that, whatever the centile, BMI decreases between 3 and 5 years. For the purposes of this analysis we considered that a child showed an early adiposity rebound if BMI at age 5 was greater than that at age 3 . The children were also grouped by body mass tertiles. The distribution of children in the body mass tertiles differed significantly according to socioeconomic status.

The statistical tests used were the $\chi^{2}$, the $\chi^{2}$ for trend, and the Kruskal-Wallis test.

\section{Results}

The prevalence of overweight at 3 years of age was $4.6 \%$; this was identical for the two sexes and did not differ according to socioeconomic status (table 1).

Adiposity rebound occurred in $30.4 \%$ of the children before age 5 . This proportion did not differ between the social groups: $30.1 \%$ in group $1,29.9 \%$ in group $2,30.2 \%$ in group 3 , $32.7 \%$ in group 4 , and 28.8 in group 5 . 
Table 1 Prevalence of excess weight at 3 years of age by social group

\begin{tabular}{ll}
\hline Social groups (n) & Excess weight, number (\%) \\
\hline Group 1 (146) & $5(3.5)$ \\
Group 2 (197) & $11(5.6)$ \\
Group 3 (139) & $6(4.3)$ \\
Group 4 (113) & $6(5.3)$ \\
Group 5 (80) & $3(3.8)$ \\
Total (675) & $31(4.6)$
\end{tabular}

Group 1 is the highest social group, group 5 the lowest. No significant difference among social groups.

Table 2 Increase in body mass index between 3 and 5 years of age by social group in children with adiposity rebound before age 5

\begin{tabular}{lrll}
\hline Social group & $n$ & $\begin{array}{l}\text { Mean }(\mathrm{SD}) \\
\left(\mathrm{kg} / \mathrm{m}^{2}\right)\end{array}$ & $\begin{array}{l}\text { Median } \\
\left(\mathrm{kg} / \mathrm{m}^{2}\right)\end{array}$ \\
\hline Groups 1 and 2 & 103 & $0.65(0.66)$ & 0.42 \\
Group 3 & 42 & $0.77(0.52)$ & 0.71 \\
Groups 4 and 5 & 60 & $0.92(1.17)$ & 0.54 \\
Total & 205 & $0.76(0.82)$ & 0.51 \\
\hline
\end{tabular}

$\mathrm{p}>0.05, \chi^{2}$, Kruskal-Wallis one way analysis of variance.

Adiposity rebound was significantly related to body mass at age $3: 41.9 \%$ of the children in the first body mass tertile (lean body mass) had an early rebound compared with $26 \%$ in the second tertile and $23.3 \%$ in the last tertile $(\mathrm{p}<0.001)$.

After controlling for body mass at age 3, the relation between socioeconomic status and presence of an early rebound remained nonsignificant.

Among the children who had adiposity rebound before age 5, mean (SD) BMI increased by $0.76(0.82) \mathrm{kg} / \mathrm{m}^{2}$ between ages 3 and 5 . In the lower socioeconomic groups a greater proportion of the children had an important increase in BMI between ages 3 and $5: 18.3 \%$ of children in the low socioeconomic group, $7.1 \%$ in the intermediate socioeconomic group, and $7.8 \%$ in the high socioeconomic group had an increase of $>1.6 \mathrm{~kg} / \mathrm{m}^{2}$ (above the 9th decile; $\mathrm{p}<0.05, \chi^{2}$ for trend). On average, BMI increase was greater in the lower socioeconomic group, whereas the median was higher in the intermediate group (table 2).

At 5 years old, the prevalence of obesity was $8.4 \%: 6.7 \%$ in the more prosperous social groups, $12.2 \%$ in the intermediate groups, and $8.8 \%$ in the least favoured groups (NS).

\section{Discussion}

The prevalence of excess weight at 3 years of age in our sample is essentially similar to that observed when the reference curves were drawn up in 1961, which is not the case at age $5 .^{10}$

At age 3 excess weight was not linked to socioeconomic status, in agreement with the results of other studies, which found no link between social status and obesity in young children. ${ }^{13}$
The proportion of children showing an early rebound $(30.4 \%)$ was very close to that found by Rolland-Cachera $(30.5 \%){ }^{8}$ The latter finding was based on data from almost 30 years ago, therefore, the proportion of early rebound has not changed with time.

This proportion is smaller with increasing body mass at age 3 . This could be explained by the phenomenon of levelling: thin children tend to normalise their body mass with an early rebound, and fat children with a delayed rebound. ${ }^{11}$

The proportion of children with adiposity rebound before age 5 is independent of socioeconomic status even after controlling for body mass. The inequalities observed in adolescence do not appear to be linked to an excess of early rebound in children in the least favoured social groups.

While early adiposity rebound is no more frequent in children from a low socioeconomic group, rapid weight increase seems more common; however, the size of our sample does not permit conclusions on this topic. The hypothesis that social inequalities for obesity observed in adolescence can partly be explained by a more rapid increase in weight after an early adiposity rebound in children of low socioeconomic status should be studied further. If this is the case, preschool children should be screened for this problem and preventive strategies accessible to these groups should be developed to prevent too rapid weight increase in children who have an adiposity rebound before 5 years of age.

We thank the Dr Jean Fontaine Foundation and the Alice and David Van Buren Foundation for their financial support and the school medical centres for their help in collecting data.

1 Sobal J, Stunkard AJ. Socioeconomic status and obesity: a review of the literature. Psychol Bull 1989;105:260-75.

2 Flegal KM, Harlan WR, Landis JR. Secular trends in body mass index and skinfold thickness with socioeconomic factors in young adult women. Am F Clin Nutr 1988;48:53543.

3 Locard E, Mamelle N, Billette A, Miginiac M, Munoz F, Rey S. Risk factors of obesity in a five year old population. Parental versus environmental factors. Int $\mathcal{f}$ Obesity 1992;16:721-9.

4 Power C, Moynihan C. Social class and changes in weightfor-height between childhood and early adulthood. Int $\mathcal{F}$ Obesity 1988;12:445-53.

5 Garn SM, Hopkins PJ, Ryan AS. Differential fatness gain of low income boys and girls. Am f Clin Nutr 1981;34:14658.

6 Lissau-Lund-Sorensen I, Sorensen TIA. Prospective study of the influence of social factors in childhood on risk of overweight in young adulthood. Int $\mathcal{F}$ Obesity 1992;16:16975.

7 Siervogel RM, Roche AF, Guo S, Mukherjee D, Chumlea C. Patterns of change in weight/stature from 2 to 18 years: findings from long-term serial data for children in the Fels longitudinal growth study. Int $\mathcal{F}$ Obesity 1991;15:479-85.

8 Rolland-Cachera MF, Deheeger M, Bellisle F, Sempé M, Guilloud-Bataille M, Patois E. Adiposity rebound in children: a simple indicator for predicting obesity. $A m \mathcal{F}$ Clin Nutr 1984;39:129-35.

9 Dietz WH. Critical periods in childhood for the development of obesity. Am f Clin Nutr 1994;59:955-9.

10 Rolland-Cachera MF, Cole TJ, Sempé M, Tichet J, Rossignol C, Charraud A. Body mass index variations: centiles from birth to 87 years. Eur F Clin Nutr 1991;45:13-21.

11 Rolland-Cachera MF. Onset of obesity assessed from the weight/stature curve in children: the need for a clear definition. Int f Obesity 1993;17:245-6. 